\title{
Carbon Supported Phosphoric Acid Catalysts for Gas-Phase Synthesis of Diesel Additives
}

\author{
Anna Grünert ${ }^{1} \cdot$ Wolfgang Schmidt ${ }^{1} \cdot$ Ferdi Schüth $^{1}$
}

Received: 29 January 2020 / Accepted: 23 March 2020 / Published online: 3 April 2020

(c) The Author(s) 2020

\begin{abstract}
Carbon supported phosphoric acid $\left(\mathrm{H}_{3} \mathrm{PO}_{4} / \mathrm{C}\right)$ was found to be a more productive catalyst for the gas-phase synthesis of the diesel fuel additive/substitute oxymethylene ethers (OME) as compared to benchmark zeolite catalysts. In this contribution, the performance of catalysts $\mathrm{H}_{3} \mathrm{PO}_{4} / \mathrm{C}$ and related $\mathrm{H}_{2} \mathrm{PO}_{4}{ }^{-} / \mathrm{C}$ and $\mathrm{HPO}_{4}{ }^{2-} / \mathrm{C}$ materials in $\mathrm{OME}$ synthesis from methanol and formaldehyde is described.
\end{abstract}

\section{Graphic Abstract}

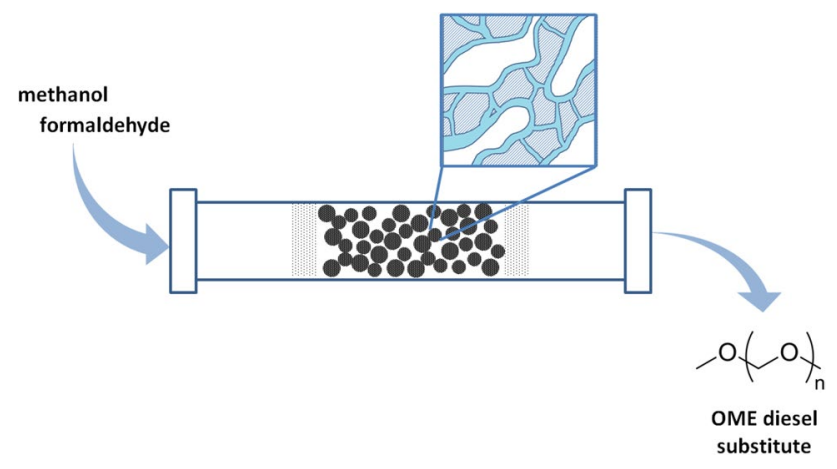

\section{Introduction}

Many efforts in research and politics are currently directed towards finding solutions for more sustainable mobility, as the transportation sector constitutes one of the main factors contributing to global greenhouse gas emission [1]. In the last decades, governments in Europe and North America

Electronic supplementary material The online version of this article (https://doi.org/10.1007/s10562-020-03200-4) contains supplementary material, which is available to authorized users.

Ferdi Schüth

schueth@mpi-muelheim.mpg.de

1 Max-Planck-Institut für Kohlenforschung, Kaiser-Wilhelm-Platz 1, 45470 Mülheim an der Ruhr, Germany have implemented increasingly strict legislation concerning levels of pollutant exhaust gases [2]. In addition to a further improvement of engines, the development of superior fuels is a viable approach in order to mitigate the emission of $\mathrm{CO}_{2}$ and other pollutants [3].

In the context of sustainability, not only the reduction of greenhouse gases, but also a shift away from fossil energy resources is desired. Both requirements can be satisfied when vehicles are fuelled with synthetic fuels on the basis of sustainably generated carbon dioxide $\left(\mathrm{CO}_{2}\right)$ and hydrogen $\left(\mathrm{H}_{2}\right)$. The use of $\mathrm{CO}_{2}$ sourced from industrial exhaust gases, biomass or via direct air capture allows reducing the overall life-cycle $\mathrm{CO}_{2}$ emissions via $\mathrm{CO}_{2}$ consumption during fuel production [4]. Hydrogen is preferably produced via water electrolysis using electricity from renewable sources.

Various $\mathrm{CO}_{2}$-based fuels are known to date, namely methane, methanol, dimethyl ether (DME), or Fischer-Tropsch (FT) fuels. Recently, the group of homologuous oxymethylene ethers ( $\mathrm{OME}, \mathrm{CH}_{3} \mathrm{O}\left(\mathrm{CH}_{2} \mathrm{O}\right)_{\mathrm{n}} \mathrm{CH}_{3}$, see Fig. 1), which can be produced from methanol and is therefore also considered as a $\mathrm{CO}_{2}$-based fuel, has gained attention due to the promising combustion characteristics as well as favourable physicochemical properties, with $n=3-5$ being the most favourable range. Combustion of neat OME or of blends with diesel fuel in conventional compression ignition engines results in a significant decrease in particulate matter emissions as compared to common diesel fuel [5-8]. Due to the absence of the common soot- $\mathrm{NO}_{\mathrm{x}}$ trade-off, which only allows 


$$
\text { fo } \ln _{\mathrm{n}} \mathrm{O}
$$

Fig. 1 Chemical structure of oxymethylene ethers, $n$ denoting the number of repeating units

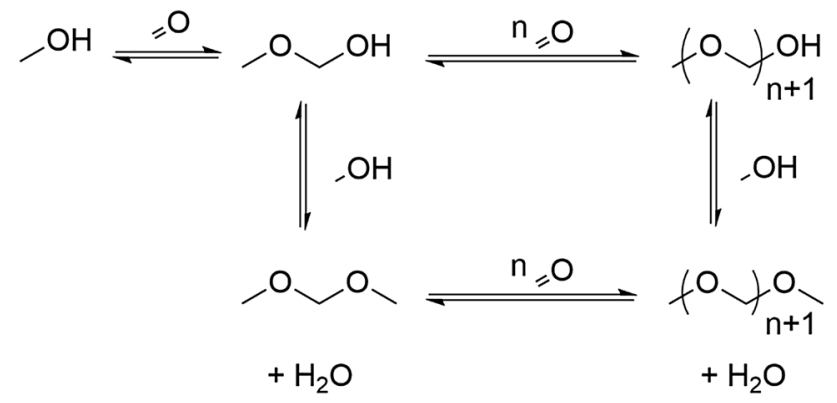

Fig. 2 Reaction equations for the synthesis of OME from methanol and formaldehyde

minimizing one component, the emission of harmful nitrous oxides $\left(\mathrm{NO}_{\mathrm{x}}\right)$ can be decreased simultaneously.

The homologous OME with a chain length of $n=3-5$ are similar to diesel fuel with respect to relevant properties, such as cetane number, flash point, boiling point, surface tension, and they comply largely with the specifications from norm EN $590[9,10]$. Neat $\mathrm{OME}_{3-5}$ or OME/diesel fuel blends can be handled with the established fuel infrastructure and can be used as drop-in fuels in conventional motors [11]. The non-toxic character of OME is a further advantage of OME.

While the mentioned characteristics suggest a low market introduction barrier for OME, its widespread use could to date not be established due to the remaining challenge to develop a cost- and energy-efficient production process. For this reason, the investigation of novel OME synthesis procedures is a highly interesting as well as relevant topic.

In literature, various studies focussing on OME liquidphase syntheses are described. Typically, methanol or $\mathrm{OME}_{1}$ [alternative nomenclature: dimethoxymethane (DMM) or methylal] is reacted with formaldehyde in batch mode. The latter reactant is typically introduced in the form of the trimer trioxane [11-21] or the polymer paraformaldehyde [22-26], which undergo acid catalysed decomposition to formaldehyde under the reaction conditions.

Also the current industrial process is based on liquidphase OME formation with trioxane as a formaldehyde source [27]. A disadvantage of this route is that it is highly energy-intensive, mainly due to the isolation of the intermediate product trioxane via distillation.

The isolation of intermediates can be circumvented by using methanol $(\mathrm{MeOH})$ and formaldehyde (FA) directly in OME formation (see Fig. 2). Even though the co-formation of water in the course of the reaction leads to lower yields of OME as opposed to the current industrial route, there is potential to overcome this drawback by separation of water and the recycling of unwanted products.

OME syntheses from $\mathrm{MeOH}$ and FA in batch mode was reported using catalysts such as zeolties [28] or exchange resins [27-31]. Furthermore, continuous-flow OME synthesis over $\mathrm{Zr}$-modified $\gamma-\mathrm{Al}_{2} \mathrm{O}_{3}[32,33]$, using methanolic or mixed aqueous methanolic solutions of formaldehyde, has been described.

In a previous study, we highlighted the gas-phase OME synthesis from $\mathrm{MeOH}$ and FA over zeolite catalysts [34]. $\mathrm{OME}_{1-3}$ could be produced at selectivities as high as $95 \%$. However, the zeolitic catalysts suffered from limited stability. Deactivation was discussed to occur as a consequence of pore blocking.

In this work, phosphoric acid supported on carbon was investigated as an alternative to zeolite catalysts for gas-phase OME synthesis. In general, supported phosphoric acid catalysts can be considered to belong to the family of supported liquid phase catalysts when the reaction temperature is above the melting point of the active phase $\left(\mathrm{H}_{3} \mathrm{PO}_{4}: 42{ }^{\circ} \mathrm{C}\right)$ [35]. Historically, phosphoric acid impregnated on kieselguhr or other silica supports-also called solid phosphoric acid (SPA) — was used in solid acid catalysis [36]. SPA is highly active in reactions such as gas-phase oligomerisation of low molecular weight olefins and benzene alkylation to ethylbenzene or cumene.

In SPA catalysts, the presence of various phosphorus containing species [37], including silicon phosphates, makes a correlation of structure or loading with activity difficult. When phosphoric acid is supported on a porous carbon $\left(\mathrm{H}_{3} \mathrm{PO}_{4} / \mathrm{C}\right)$ and used without further treatment at elevated temperatures, no mixed phases or phosphorylation of the support is expected to occur. This renders analysis, e.g. via ${ }^{31} \mathrm{P}$ MAS NMR analysis, significantly more simple. Furthermore, the $\mathrm{H}_{3} \mathrm{PO}_{4} / \mathrm{C}$ catalysts can be synthesised from cheap and readily available materials via simple synthesis protocols. To date, only few reports of carbon supported phosphoric acid catalysts have been published [38].

In this work, the activity of $\mathrm{H}_{3} \mathrm{PO}_{4} / \mathrm{C}$ catalysts in the formation of oxymethylene ethers from methanol and formaldehyde and the activity of related hydrogen phosphates $\mathrm{H}_{2} \mathrm{PO}_{4}{ }^{-}$and $\mathrm{HPO}_{4}{ }^{2-}$ was evaluated. Furthermore, a superior deactivation resistance of $\mathrm{H}_{3} \mathrm{PO}_{4} / \mathrm{C}$ was demonstrated. As zeolites constitute a common alternative to phosphoric acid based systems in industrial processes [39], the performance 
of $\mathrm{H}_{3} \mathrm{PO}_{4} / \mathrm{C}$ was additionally compared to a benchmark zeolite catalyst.

\section{Results and Discussion}

\subsection{Catalyst Characterisation}

For the preparation of supported catalysts, it is of interest to firstly study the textural properties of the chosen support. The nitrogen physisorption isotherm of the pristine granular carbon (denoted as C-granule) shows typical features of a micro- and mesoporous material (see Fig. 3). While the steep increase at low $\mathrm{N}_{2}$ pressure indicates the presence of micropores, the occurrence of a hysteresis loop is typical for mesoporous materials. Accordingly, the shape of the hysteresis loop, corresponding to an H4-type hysteresis loop according to IUPAC classification, is characteristic for materials containing micro- and mesopores [40]. Furthermore, a total pore volume of $1.1 \mathrm{~cm}^{3} / \mathrm{g}$ was determined from physisorption data. According to thermogravimetric analysis (see Fig. S1), the granular carbon activated as described in the experimental section has a water content of $6.2 \%$ and an ash content of $2.1 \%$.

The impact of phosphoric acid impregnation on the sorption properties of the materials was exemplarily studied using catalyst $0.9 \_\mathrm{H}_{3} \mathrm{PO}_{4} / \mathrm{C}$. The filling of a large share of pores upon impregnation is reflected by a pronounced decrease of total pore volume from 1.1 to $0.3 \mathrm{~cm}^{3} / \mathrm{g}$. Accordingly, the BET surface area decreased from 1573 to $203 \mathrm{~m}^{2} / \mathrm{g}$. As BET surface area has a limited physical validity for microporous materials, it is only specified as a means for comparison of the materials.

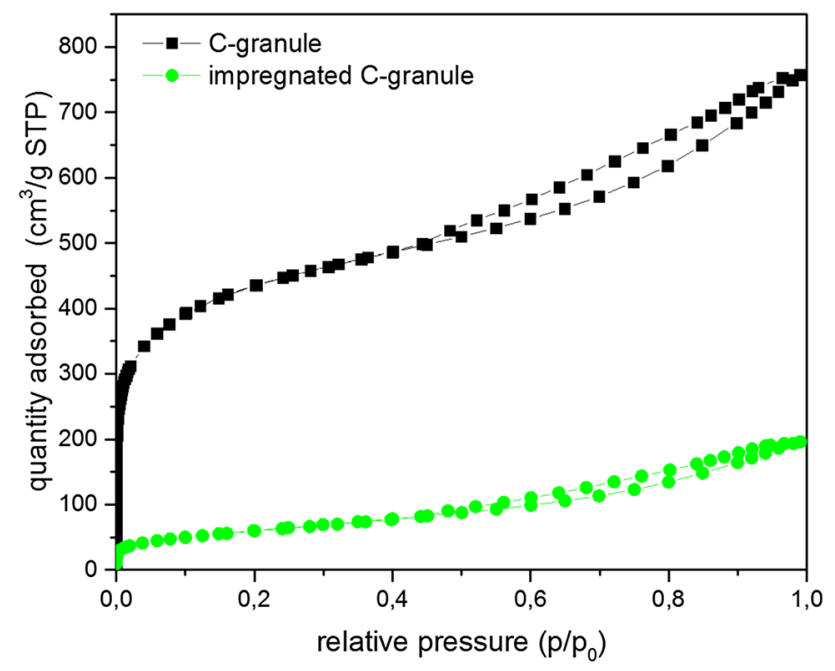

Fig. $3 \mathrm{~N}_{2}$ physisorption isotherm of the granular carbon support and the impregnated sample $0.9 \_\mathrm{H}_{3} \mathrm{PO}_{4} / \mathrm{C}$
For the interpretation of $\mathrm{N}_{2}$-physisorption of supported phosphoric acid, it should be kept in mind that $\mathrm{H}_{3} \mathrm{PO}_{4}$ is solid at measurement temperature $\left(-196^{\circ} \mathrm{C}\right)$, but will be liquid under reaction conditions $\left(130{ }^{\circ} \mathrm{C}\right.$, melting point $\mathrm{H}_{3} \mathrm{PO}_{4}: 42{ }^{\circ} \mathrm{C}$ ) [35]. The decrease of pore volume evidenced in physisorption analysis hence is not regarded as a pore blocking, but rather gives information about the filling degree of the pores.

In ${ }^{31} \mathrm{P}$ MAS NMR spectra of the as synthesised catalysts, two lines are present (see Fig. 4). The line at about 0 ppm can readily be assigned to ortho-phosphoric acid $\left(\mathrm{H}_{3} \mathrm{PO}_{4}\right)$ as the spectra are referenced to $85 \% \mathrm{H}_{3} \mathrm{PO}_{4}$. The second signal at about $-13 \mathrm{ppm}$ is related to a condensed phosphoric acid species, supposedly pyrophosphoric acid. As the chemical shifts of condensed phosphates are dependent on the local environment [41], it is not surprising that different chemical shifts have been reported for supported pyrophosphoric acid $\left(\mathrm{H}_{4} \mathrm{P}_{2} \mathrm{O}_{7}\right)$, depending on the support material. While spectra of phosphated zeolites feature lines at both $-5 \mathrm{ppm}$ and - 13 ppm [42], in spectra of the SPA catalyst $\left(\mathrm{H}_{3} \mathrm{PO}_{4} /\right.$ $\mathrm{SiO}_{2}$ ) the line at $-5 \mathrm{ppm}$ is not observed [37]. It may be supposed that SPA is a valid reference to $\mathrm{H}_{3} \mathrm{PO}_{4} / \mathrm{C}$. Hence, the observed line at $-13 \mathrm{ppm}$ indicates the presence of pyrophosphoric acid. The absence of further signals suggests that no polyphosphates are present.

As the integrals of the lines can be assumed to be proportional to the amount of phosphorus (with $1 \mathrm{P}$ per $\mathrm{H}_{3} \mathrm{PO}_{4}$ and $2 \mathrm{P}$ per $\mathrm{H}_{4} \mathrm{P}_{2} \mathrm{O}_{7}$ ), the major share of phosphorus is present in the form of phosphoric acid.

Under reaction conditions, the catalyst is exposed to gaseous polar components, including water, at elevated temperatures $\left(130^{\circ} \mathrm{C}\right)$. Both ortho- and pyrophosphoric acid
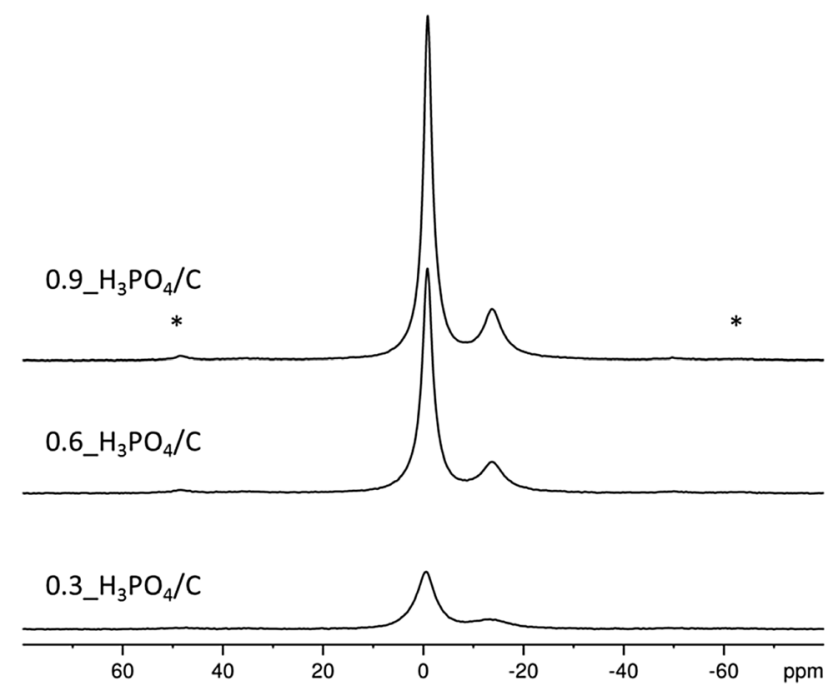

Fig. 4 Stacked ${ }^{31} \mathrm{P}$ MAS NMR spectra of $\mathrm{H}_{3} \mathrm{PO}_{4} / \mathrm{C}$ catalysts with varying loading. Positions of spinning side bands are marked with asterisks. The numbers denote loading in $\left[\mathrm{g} \mathrm{H}_{3} \mathrm{PO}_{4} / \mathrm{g} \mathrm{C}\right]$ 
have melting points below the reaction temperature $\left(\mathrm{H}_{3} \mathrm{PO}_{4}\right.$ : $42.3{ }^{\circ} \mathrm{C}, \mathrm{H}_{4} \mathrm{P}_{2} \mathrm{O}_{7}: 71.5^{\circ} \mathrm{C}$ ) and are hygroscopic. It is therefore expected that firstly, the active components melt upon preheating the catalyst, and secondly, a concentrated solution is formed on the catalyst in the presence of water. As the condensation of phosphoric acid to pyrophosphoric acid is a reversible reaction, pyrophosphoric acid can undergo hydrolysis to release ortho-phosphoric acid [35]. This may be expected to also occur under reaction conditions.

A linear correlation was found when the amount of phosphorus detected via ${ }^{31}$ P MAS NMR, expressed by the integral over the range of [ $80 \mathrm{ppm},-80 \mathrm{ppm}$ ], was related to the expected amount, as calculated from incipient wetness impregnation, for a range of different samples (see Fig. S3). This indicates that the complete amount of phosphorus is detected via ${ }^{31}$ P MAS NMR.

\subsection{Catalytic Tests}

\subsubsection{Preliminary Studies of Exemplary $\mathrm{H}_{3} \mathrm{PO}_{4} / \mathrm{C}$ Catalyst}

Prior to catalytic tests of the impregnated catalysts, the inertness of the support was confirmed. In a blank test run under reaction conditions, no conversion over the granular carbon was detected. However, it was observed that the carbon material strongly interacts with the reagents methanol and formaldehyde (see Fig. S2). In the first data point after the start of the reaction, it is normal to see a drop in reactant concentration due to the flushing out of the inert gas from the reactor. However, the detected reagent concentrations increase only slowly thereafter, reflecting the ongoing adsorption of reagents inside the porous material. It should be noted that the carbon balance was calculated analogously for all test runs and the behaviour described above was only observed to a marginal extent when a reaction occurred.

As a standard $\mathrm{H}_{3} \mathrm{PO}_{4} / \mathrm{C}$ catalyst, a material with a loading of $0.9 \mathrm{~g} \mathrm{H}_{3} \mathrm{PO}_{4} / \mathrm{g} \mathrm{C}$ was prepared. It was used to test the general suitability of $\mathrm{H}_{3} \mathrm{PO}_{4} / \mathrm{C}$ catalysts in the gas-phase synthesis of OME from $\mathrm{MeOH}$ and FA. Conversion levels of $47 \%$ and OME selectivity of $95 \%$ were measured at moderate $\mathrm{WHSV}_{\mathrm{FA}}\left(1.1 \mathrm{~h}^{-1}\right.$, see Fig. S4, left). $\mathrm{OME}_{1}, \mathrm{OME}_{2}$ and the side product methyl formate was formed. While the initial conversion is lower as compared to benchmark zeolites investigated in a previous study, the initial selectivity is improved, leading to a comparable initial OME yield [34].

The moderate acid strength of phosphoric acid $\left(\mathrm{pK}_{\mathrm{a} 1}=2.1\right)$ appears to be sufficient to reach the benchmark performance. In analogy to the previously studied series of zeolite catalysts, the absence of strongly acidic groups prevents the excessive formation of the by-product methyl formate and the occurrence of dimethyl ether.

In order to evaluate the robustness of the $\mathrm{H}_{3} \mathrm{PO}_{4} / \mathrm{C}$ system and the sensitivity of the reaction towards decreased residence times, the exemplary catalyst $0.9 \_\mathrm{H}_{3} \mathrm{PO}_{4} / \mathrm{C}$ was also tested at the maximal $\mathrm{WHSV}_{\mathrm{FA}}$ that can be realised in the test set-up without raising the reactant concentration $\left(\mathrm{WHSV}_{\mathrm{FA}}=42.7 \mathrm{~h}^{-1}\right)$. The catalyst in its granular form showed a drop in conversion to $31 \%$, and the side reaction towards methyl formate was supressed (see Fig. S4). At so strongly decreased residence time, one would expect a much higher drop in conversion. Obviously, at long residence time the reaction reaches already equilibrium after a short bedlength, so that even at very high flow rates a substantial conversion level can be maintained.

At such high flow rates, the granular support suffers from some mass transfer limitation: When the catalyst was ground to a fine powder prior to testing, the conversion was appreciably higher at the same residence time, and a comparable performance to the moderate $\mathrm{WHSV}_{\mathrm{FA}}$ recurred.

As a comparable catalyst performance is observed at moderate as well as increased $\mathrm{WHSV}_{\mathrm{FA}}$, it may be concluded that the reaction is so fast as to not allow realising lowered conversion levels within the limits of the catalytic testing set-up. All further tests were therefore carried out at moderate $\operatorname{WHSV}_{\mathrm{FA}}\left(1.1 \mathrm{~h}^{-1}\right)$ in order to avoid interference with mass transfer limitations of the granular catalyst.

\subsection{Impact of $\mathrm{H}_{3} \mathrm{PO}_{4}$ Loading}

In order to test the influence of phosphoric acid loading on the catalyst performance, two further catalysts with varying phosphoric acid loading were prepared, representing a range of 0.9-0.04 $\mathrm{g} \mathrm{H}_{3} \mathrm{PO}_{4} / \mathrm{g} \mathrm{C}$.

In contrast to zeolites, a significant change in acid strength upon variation of acid concentration is not expected for supported phosphoric acid catalysts. This can be rationalised by the assumption that unlike protons in zeolites, the phosphoric acid is mobile and therefore the individual molecules are not significantly influenced by the local environment.

The catalysts showed similar performance over the whole range of phosphoric acid loading (see Fig. 5). For all test runs, the conversion and selectivity reached a constant level after $30 \mathrm{~min}$ of reaction time and showed no change until the end of measurement after $1.5 \mathrm{~h}$ reaction time. It can be regarded as an (initial) steady-state conversion/selectivity. The independence of performance with respect to the active phase loading may be an indication that the reaction is running close to equilibrium. As described above, it was not feasible for the $\mathrm{H}_{3} \mathrm{PO}_{4} / \mathrm{C}$ system to perform catalytic tests at lower conversion levels.

\subsection{Sodium Phosphates}

As phosphoric acid is a polyprotic acid, it is of interest to also study the contributions of the related proton donating species, namely dihydrogen phosphate $\left(\mathrm{H}_{2} \mathrm{PO}_{4}{ }^{-}\right)$and 


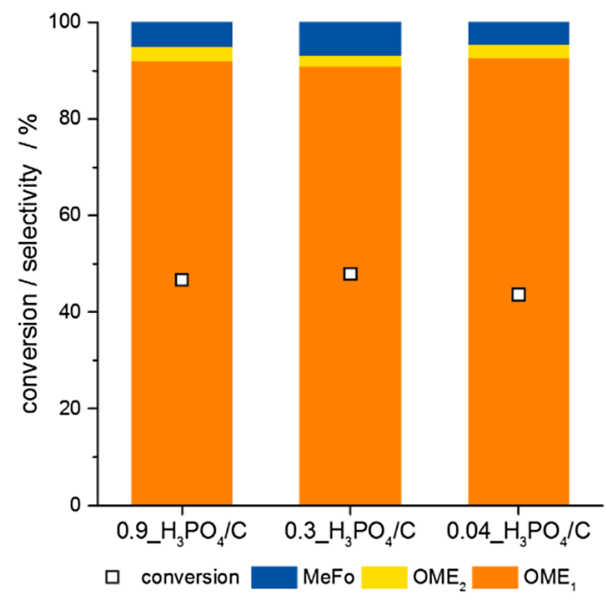

Fig. 5 Initial conversion and selectivity after $1 \mathrm{~h}$ reaction time of $\mathrm{H}_{3} \mathrm{PO}_{4} / \mathrm{C}$ catalysts with varying phosphoric acid loading. Reaction conditions: $500 \mathrm{mg}$ catalyst, $10 \mathrm{bar}, 130^{\circ} \mathrm{C}, \mathrm{WHSV}_{\mathrm{FA}}=1.1$

hydrogen phosphate $\left(\mathrm{HPO}_{4}{ }^{2-}\right)$. Their varying deprotonation barriers are reflected in the different dissociation constants of phosphoric acid of $\mathrm{pK}_{\mathrm{a} 1}=2.16, \mathrm{pK}_{\mathrm{a} 2}=7.21$ and $\mathrm{pK}_{\mathrm{a} 3}=12.32$ (at $25^{\circ} \mathrm{C}$ ) [35]. Monosodium phosphate and disodium phosphate were used as representative salts. A series of catalysts containing equimolar amounts $(700 \mu \mathrm{mol} / \mathrm{g} \mathrm{C})$ of $\mathrm{H}_{3} \mathrm{PO}_{4}$, $\mathrm{NaH}_{2} \mathrm{PO}_{4}$ or $\mathrm{Na}_{2} \mathrm{HPO}_{4}$, respectively, was prepared by incipient wetness impregnation of the respective components.

Out of the series of catalysts, $\mathrm{H}_{3} \mathrm{PO}_{4}$ shows the highest activity in OME formation. In comparison to the $\mathrm{H}_{3} \mathrm{PO}_{4} / \mathrm{C}$ catalysts, activity of the sodium phosphate based catalysts is significantly reduced (see Fig. 6, left). Conversion drops successively from $\mathrm{H}_{3} \mathrm{PO}_{4}$ to $\mathrm{Na}_{2} \mathrm{HPO}_{4}$. For $\mathrm{NaH}_{2} \mathrm{PO}_{4} / \mathrm{C}$, the conversion is decreased by $77 \%$ to a level of $10 \%$. The material $\mathrm{Na}_{2} \mathrm{HPO}_{4} / \mathrm{C}$ is inactive in the studied reaction.

The sodium exchange also influences the catalyst selectivity. In case of $\mathrm{NaH}_{2} \mathrm{PO}_{4} / \mathrm{C}$, the irreversible formation of methyl formate from formaldehyde is more pronounced which leads to a decrease in overall OME selectivity. Interestingly, a larger share of $\mathrm{OME}_{2}$ is formed as compared to the $\mathrm{H}_{3} \mathrm{PO}_{4} / \mathrm{C}$ system. Presumably, this is due to the lower level of conversion which favours the chain growth reaction. The product distribution of $\mathrm{Na}_{2} \mathrm{HPO}_{4} / \mathrm{C}$ is not meaningful as the overall conversion was below $1 \%$, not allowing reliable quantification of reaction products. In analogy to the test runs using $\mathrm{H}_{3} \mathrm{PO}_{4} / \mathrm{C}$, conversion and selectivity reached an (initial) steady-state after $30 \mathrm{~min}$ of reaction time.

As the conversion over $\mathrm{NaH}_{2} \mathrm{PO}_{4} / \mathrm{C}$ is lower than over the $\mathrm{H}_{3} \mathrm{PO}_{4} / \mathrm{C}$ system, it may be argued that the reaction does not reach equilibrium in this case. The conversion should hence be sensitive to reaction conditions such as residence time and catalyst loading. Indeed, the increase of $\mathrm{NaH}_{2} \mathrm{PO}_{4} / \mathrm{C}$ loading from 0.08 to $0.3 \mathrm{~g} / \mathrm{g}$ C yielded a doubling of conversion and an increase in OME selectivity (see Fig. 6, right).

\subsection{Comparison with Benchmark Zeolite}

In our previous study on gas-phase OME synthesis from methanol and formaldehyde, we described the correlation between acid properties and catalyst activity for a range of zeolites. The best performing zeolites were H-MOR-40 and Silicalite-1 [34].

In order to evaluate the general performance of the $\mathrm{H}_{3} \mathrm{PO}_{4} / \mathrm{C}$ system with respect to the well-established group of zeolite catalyst, the performance of the phosphoric acid based catalysts was compared with that of H-MOR-40. H-MOR-40 was chosen as it shows a superior stability as compared to Silicalite-1. Furthermore, H-MOR-40 is a classic Brønsted acidic zeolite and is hence more easily compared to the Brønsted acidic phosphoric acid catalyst. The catalyst stability and deactivation behaviour were chosen as parameters to be compared.

For a fair comparison, a similar amount of Brønsted acidic sites should be present in the reactor. The total amount of acid sites of $\mathrm{H}-\mathrm{MOR}-40$ was determined via $\mathrm{NH}_{3}$-TPD to
Fig. 6 Initial conversion and selectivity of granular carbon loaded with $700 \mu \mathrm{mol} / \mathrm{g} \mathrm{C}$ of phorphoric acid, $\mathrm{NaH}_{2} \mathrm{PO}_{4}$, or $\mathrm{Na}_{2} \mathrm{HPO}_{4}$ (left) and $\mathrm{Na}_{2} \mathrm{HPO}_{4} / \mathrm{C}$ catalysts with different loading (right) after $1 \mathrm{~h}$ reaction time. Reaction conditions: $500 \mathrm{mg}$ catalyst, 10 bar, $130{ }^{\circ} \mathrm{C}$, $\mathrm{WHSV}_{\mathrm{FA}}=1.1$
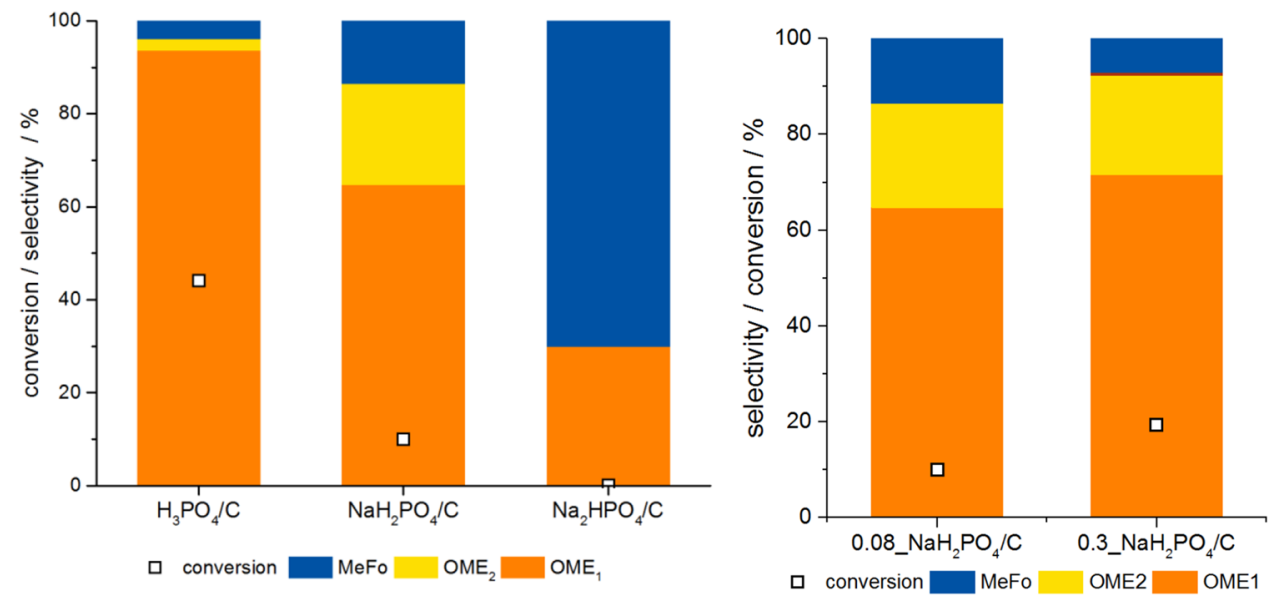
be $385 \mu \mathrm{mol}$ acid sites/g zeolite [34]. An analogous characterisation of $\mathrm{H}_{3} \mathrm{PO}_{4} / \mathrm{C}$ catalysts with $\mathrm{NH}_{3}$-TPD is difficult due to expected changes in the catalyst state upon thermal activation. Presumably, a change in acid site concentration and strength as compared to the as synthesised catalyst will occur due to condensation of $\mathrm{H}_{3} \mathrm{PO}_{4}\left(\mathrm{pK}_{\mathrm{a} 1}\right.$ of 2.16) to $\mathrm{H}_{4} \mathrm{P}_{2} \mathrm{O}_{7}\left(\mathrm{pK}_{\mathrm{a} 1}\right.$ of 0.91) [35]. As reasoned above, phosphoric acid may be assumed to be the predominant active species under reaction conditions. Therefore, the acid site concentration was directly related to the phosphoric acid loading. It should be acknowledged that this comparison is based on the before mentioned assumptions and will therefore not yield exact numbers, but acid site concentrations in the same range for both catalysts.

A representative sample of $\mathrm{H}_{3} \mathrm{PO}_{4} / \mathrm{C}$ with $385 \mu \mathrm{mol}$ acid sites/g sample was prepared by dilution of the $0.3{ }_{-} \mathrm{H}_{3} \mathrm{PO}_{4} / \mathrm{C}$ with the carbon support material. In order to achieve a satisfactory mixing and to yield a particle size similar to $\mathrm{H}-\mathrm{MOR}-40$, the $\mathrm{H}_{3} \mathrm{PO}_{4} / \mathrm{C}$ sample was ground in a mortar prior to catalytic testing.

In the deactivation study presented in Fig. 7, the stability of the $\mathrm{H}_{3} \mathrm{PO}_{4} / \mathrm{C}$ catalyst was identified to be superior to the benchmark zeolite H-MOR-40. The activity of the zeolitic catalyst decreased to $50 \%$ of its steady-state conversion after $36 \mathrm{~h}$ reaction time. In contrast, the $\mathrm{H}_{3} \mathrm{PO}_{4} / \mathrm{C}$ catalyst kept $87 \%$ of its steady-state conversion up to the end of the measurement at $95 \mathrm{~h}$ reaction time. The selectivity is hardly affected by the deactivation.

In the previous study, pore blocking was argued to likely be a main cause for deactivation of zeolitic catalysts [34]. The tested zeolites were purely microporous and

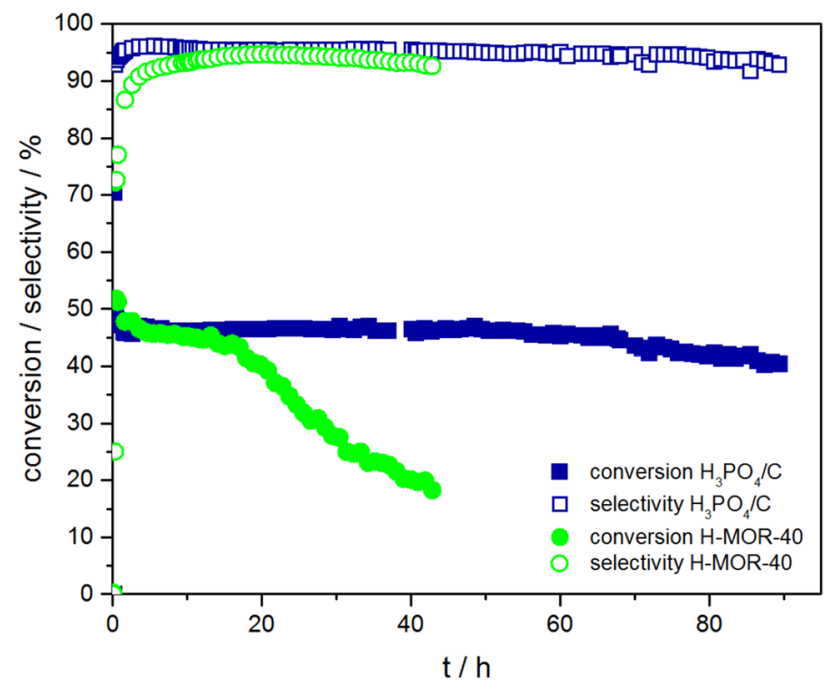

Fig. 7 Conversion and overall OME selectivity as a function of time for $\mathrm{H}_{3} \mathrm{PO}_{4} / \mathrm{C}$ and $\mathrm{H}-\mathrm{MOR}-40$ catalysts with the same concentration of acid sites. Reaction conditions: $500 \mathrm{mg}$ catalyst, $10 \mathrm{bar}, 130{ }^{\circ} \mathrm{C}$, $\mathrm{WHSV}_{\mathrm{FA}}=1.1$ therefore susceptible to deactivation via pore blocking. In contrast, the $\mathrm{H}_{3} \mathrm{PO}_{4} / \mathrm{C}$ catalysts used in this study have a micro- and mesoporous carbon matrix, which facilitates the access to the active species. Furthermore, phosphoric acid as the active phase is in the liquid state under reaction conditions and is mobile, presumably leading to a good dispersion of the active phase. Additionally, reagents may diffuse into the active phase. In this respect, it is not surprising to observe deviating deactivation behaviour of the two fundamentally different solid acid catalysts. Potentially, a combination of the described properties of supported phosphoric acid is the basis for the deactivation resistance of the catalyst.

\section{Conclusions}

Carbon supported phosphoric acid catalysts are easily synthesised from cheap and readily available materials. Due to the presence of a limited number of phosphor containing species, the catalysts can readily be analysed using ${ }^{31} \mathrm{P}$ MAS NMR.

In this study, the activity of $\mathrm{H}_{3} \mathrm{PO}_{4} / \mathrm{C}$ catalyst in the gasphase synthesis of OMEs from methanol and formaldehyde was studied in detail. $\mathrm{H}_{3} \mathrm{PO}_{4} / \mathrm{C}$ catalysts have a comparable initial OME yield and overall steady-state performance as benchmark zeolites.

As the acid loading of $\mathrm{H}_{3} \mathrm{PO}_{4} / \mathrm{C}$ catalysts can be changed independently of acid strength, it could be demonstrated that the catalyst initial activity is not correlated with the acid loading under the studied reaction conditions. This indicates that the reaction is running close to equilibrium. This was supported by the investigation of sodium phosphate catalysts. The acid strength of the monosodium phosphate $\left(\mathrm{pK}_{\mathrm{a}}=7.21\right)$ was demonstrated to be too low to reach reaction equilibrium. Accordingly, no reaction occurred over the disodium phosphate catalysts $\left(\mathrm{pK}_{\mathrm{a}}=12.32\right)$.

Two representative materials of the $\mathrm{H}_{3} \mathrm{PO}_{4} / \mathrm{C}$ and the zeolite catalyst families were compared in a deactivation study. At a comparable acid site concentration, the $\mathrm{H}_{3} \mathrm{PO}_{4} / \mathrm{C}$ catalyst showed superior stability over H-MOR-40 zeolite. It was argued that various factors including the presence of mesopores in the matrix and the liquid state of the active phase may facilitate the deactivation resistance of the $\mathrm{H}_{3} \mathrm{PO}_{4} / \mathrm{C}$ catalyst.

In this study, we highlight the benefits of the long-known catalyst system of supported phosphoric acid catalysts using activated carbon as a support. Although supported phosphoric acid, typically supported on silica, has in many cases been replaced by zeolite catalysts in acid catalysis, this work demonstrates a reaction in which the use of $\mathrm{H}_{3} \mathrm{PO}_{4}$ based catalyst is advantageous. 


\section{Experimental}

\subsection{Materials}

The granular activated carbon TC303 was kindly supplied by Silcarbon. The grain size is $1-2 \mathrm{~mm}$. It was activated by repeatedly adding hot distilled water $\left(90^{\circ} \mathrm{C}\right)$, vigorously shaking and decanting the supernatant until the supernatant was clear. Subsequently, the granules were dried at $80{ }^{\circ} \mathrm{C}$ until no change in mass was observed. The zeolite $\mathrm{H}-\mathrm{MOR}$ with a $\mathrm{SiO}_{2} / \mathrm{Al}_{2} \mathrm{O}_{3}$-ratio of 40 (named H-MOR-40) was kindly supplied by Südchemie (now Clariant). 85\% aqueous phosphoric acid solution was purchased from Alfa Aesar, Monosodium phosphate (>99.0\%) and disodium phosphate $(99+\%)$ were purchased from Sigma Aldrich and used as supplied.

\subsection{Preparation of $\mathrm{H}_{3} \mathrm{PO}_{4} / \mathrm{C}$ Catalysts via Incipient Wetness Impregnation}

$1 \mathrm{~g}$ of activated carbon granules was impregnated with $1.67 \mathrm{ml}$ of aqueous solution, corresponding to the filling of the support pore volume. The solution contained the active component, $\mathrm{H}_{3} \mathrm{PO}_{4}, \mathrm{NaH}_{2} \mathrm{PO}_{4}$ or $\mathrm{Na}_{2} \mathrm{HPO}_{4}$, in varying concentrations depending on the targeted loading. The carbon granules were supplied in a centrifuge tube and the solution was added dropwise with repeated shaking of the tube allowing homogeneous impregnation. The impregnated samples are denoted $\mathrm{x}_{-} \mathrm{H}_{3} \mathrm{PO}_{4} / \mathrm{C}$, the prefix $\mathrm{x}$ indicating the $\mathrm{H}_{3} \mathrm{PO}_{4}$ loading in $\left[\mathrm{g} \mathrm{H}_{3} \mathrm{PO}_{4} / \mathrm{g} \mathrm{C}\right.$. Analogous nomenclature was used for $\mathrm{NaH}_{2} \mathrm{PO}_{4}$ and $\mathrm{Na}_{2} \mathrm{HPO}_{4}$ based sample. All samples were dried at $130{ }^{\circ} \mathrm{C}$ overnight.

\subsection{Characterisation of Samples}

${ }^{31} \mathrm{P}$ MAS NMR spectra were recorded on a Bruker Avance III HD 500WB spectrometer using a double-bearing MAS probe (DVT BL4) at a resonance frequency of $202.5 \mathrm{MHz}$. The spectra were measured by applying single $\pi / 2$-pulses $(3.0 \mu \mathrm{s})$ with a recycle delay of $10 \mathrm{~s}$ (32 scans) at a spinning rate of $10 \mathrm{kHz}$. High-power proton decoupling (spinal64) was applied. Prior to the measurements the samples were dried at $130{ }^{\circ} \mathrm{C}$ for $12 \mathrm{~h}$. The spectra were referenced with respect to $85 \%$ aqueous $\mathrm{H}_{3} \mathrm{PO}_{4}$ using solid $\mathrm{NH}_{4} \mathrm{H}_{2} \mathrm{PO}_{4}$ as secondary reference $(\delta=0.81 \mathrm{ppm})$.

Nitrogen physisorption was studied using a Micromeritics 3 Flex device. Samples were activated at $250{ }^{\circ} \mathrm{C}$ for $8 \mathrm{~h}$ in the Smart VacPrep unit. Isotherms were measured at $77.4 \mathrm{~K}$. Data evaluation was performed using the provided Microactive software package. The total pore volume was determined at $\mathrm{p} / \mathrm{p}^{0}=0.95$.
Thermogravimetric analysis (TGA) was performed using a NETZSCH STA 449 F3 Jupiter thermal analysis device. Approximately $3 \mathrm{mg}$ of carbon were heated in a stream of $40 \mathrm{~mL} / \mathrm{min}$ synthetic air with an additional protective flow of $20 \mathrm{~mL} / \mathrm{min}$ of $\arg$ on and a heating ramp of $10^{\circ} \mathrm{C} / \mathrm{min}$. Data was collected in the range of $45-1000{ }^{\circ} \mathrm{C}$.

\subsection{Catalytic Tests}

The $\mathrm{H}_{3} \mathrm{PO}_{4} / \mathrm{C}$ catalysts were tested in a continuous flow fixed-bed reactor under 10 bar pressure (see Fig. S5). The reactant solution with a reactant ratio of $1.5 \mathrm{~g} \mathrm{FA} / \mathrm{g} \mathrm{MeOH}$ was supplied via an HPLC pump and evaporated into a stream of carrier gas $\left(5 \% \mathrm{CH}_{4} / \mathrm{N}_{2}\right)$. The reactant mixture was previously prepared by refluxing $120 \mathrm{~g}$ paraformaldehyde (prilled, Sigma) in $100 \mathrm{ml}$ methanol (Honeywell Riedel-de-Haën) for $24 \mathrm{~h}$. Its composition of $60 \mathrm{wt} \% \mathrm{FA}$, $38 \mathrm{wt} . \% \mathrm{MeOH}$ and $2 \mathrm{wt} . \% \mathrm{H} 2 \mathrm{O}$ was determined via iodometry and Karl-Fischer titration.

The catalyst bed, containing the sample diluted with inert material silicon carbide in a 6:1 SiC:catalyst mass ratio, was heated at $130{ }^{\circ} \mathrm{C}$. All connecting tubes and valves were kept at $170{ }^{\circ} \mathrm{C}$ in order to prevent polymerization of FA and condensation of $\mathrm{MeOH}$ and reaction products. The weight hourly space velocity of formaldehyde $\left(\mathrm{WHSV}_{\mathrm{FA}}\right)$ is defined as $\mathrm{g}_{\text {(formaldehyde) }} \times \mathrm{g}_{\text {(cat) }}{ }^{-1} \times \mathrm{h}^{-1}$ and is specified in units of $\mathrm{h}^{-1}$. The product stream was analysed by online-gas chromatography using an Agilent $6890 \mathrm{~N}$ device. Separation was performed over a DB-WAX capillary column and products were analysed via TCD (for FA and $\mathrm{H}_{2} \mathrm{O}$ ) and FID (for other components) detectors. The calibration and analysis procedure is described in detail elsewhere [34].

Acknowledgements Open access funding provided by Projekt DEAL. The authors thank the Max Planck Society and the Fonds der Chemischen Industrie (FCI) for financial support and B. Zibrowius for ${ }^{31} \mathrm{P}$ MAS NMR spectroscopy.

\section{Compliance with Ethical Standards}

Conflict of interest There are no conflicts to declare.

Open Access This article is licensed under a Creative Commons Attribution 4.0 International License, which permits use, sharing, adaptation, distribution and reproduction in any medium or format, as long as you give appropriate credit to the original author(s) and the source, provide a link to the Creative Commons licence, and indicate if changes were made. The images or other third party material in this article are included in the article's Creative Commons licence, unless indicated otherwise in a credit line to the material. If material is not included in the article's Creative Commons licence and your intended use is not permitted by statutory regulation or exceeds the permitted use, you will need to obtain permission directly from the copyright holder. To view a copy of this licence, visit http://creativecommons.org/licenses/by/4.0/. 


\section{References}

1. IPoCC (2014) Climate change 2014: mitigation of climate change. Contribution of working group III to the fifth assessment report of the intergovernmental panel on climate change (IPCC), New York

2. Deutschmann O, Grunwaldt J-D (2013) Chem Ing Tech 85:595-617

3. Tagungsbericht. in 36. Internat. Wiener Motorensymposium. 2015. Wien.

4. Deutz S, Bongartz D, Heuser B, Kätelhön A, Schulze Langenhorst L, Omari A, Walters M, Klankermayer J, Leitner W, Mitsos A, Pischinger S, Bardow A (2018) Energy Environ Sci 11:331-343

5. Pélerin D, Gaukel K, Härtl M, Wachtmeister G (2017) Recent results of the sootless diesel fuel oxymethylene ether. In: Liebl J, Beidl C (eds) Internationaler Motorenkongress 2017. Springer Fachmedien Wiesbaden, Wiesbaden, pp 439-456.

6. Härtl M, Seidenspinner P, Jacob E, Wachtmeister G (2015) Fuel 153:328-335

7. Pellegrini L, Marchionna M, Patrini R, Florio S (2013) SAE Technical Paper, 2013-01-1035

8. Lumpp B (2011) MTZ Worldwide 72:34-38

9. EN 590 Automotive fuels-diesel-requirements and test methods. ECF Standardization (Ed), Brussels, Belgium

10. Lautenschütz L, Oestreich D, Seidenspinner P, Arnold U, Dinjus E, Sauer J (2016) Fuel 173:129-137

11. Lautenschütz L, Oestreich D, Haltenort P, Arnold U, Dinjus E, Sauer J (2017) Fuel Process Technol 165:27-33

12. Burger J, Ströfer E, Hasse H (2012) Ind Eng Chem Res 51:12751-12761

13. Cao J, Zhu H, Wang H, Huang L, Qin Z, Fan W, Wang J (2014) Ranliao Huaxue Xuebao 42:986-993

14. Fu WH, Liang XM, Zhang H, Wang YM, He MY (2015) Chem Commun 51:1449-1452

15. Schelling H, Stroefer E, Pinkos R, Haunert A, Tebben G-D, Hasse $\mathrm{H}$, Blagov S (2006) Method for producing polyoxymethylene dimethyl ethers from methylal and trioxane in the presence of an acidic catalyst. WO2006045506A1

16. Wu J, Zhu H, Wu Z, Qin Z, Yan L, Du B, Fan W, Wang J (2015) Green Chem 17:2353-2357

17. Wu Q, Wang M, Hao Y, Li H, Zhao Y, Jiao Q (2014) Ind Eng Chem Res 53:16254-16260

18. Wu Y, Li Z, Xia C (2016) Ind Eng Chem Res 55:1859-1865

19. Xue Z, Shang H, Xiong C, Lu C, An G, Zhang Z, Cui C, Xu M (2017) RSC Adv 7:20300-20308

20. Xue Z, Shang H, Zhang Z, Xiong C, Lu C, An G (2017) Energy Fuels 31:279-286
21. Yang Z, Hu Y, Ma W, Qi J, Zhang X (2017) Chem Eng Technol 40:1784-1791

22. Liu F, Wang T, Zheng Y, Wang J (2017) J Catal 355:17-25

23. Liu Y, Wang Y, Cai W (2019) Trans Tianjin Univ 25:1-8

24. Shi G-F, Miao J, Wang G-Y, Su J-M, Liu H-X (2015) Asian J Chem 27:2149-2153

25. Zhao Y, Xu Z, Chen H, Fu Y, Shen J (2013) J Energy Chem 22:833-836

26. Zheng Y, Tang Q, Wang T, Liao Y, Wang J (2013) Chem Eng Technol 36:1951-1956

27. Ouda M, Yarce G, White RJ, Hadrich M, Himmel D, Schaadt A, Klein H, Jacob E, Krossing I (2017) React Chem Eng 2:50-59

28. Oestreich D, Lautenschütz L, Arnold U, Sauer J (2017) Chem Eng Sci 163:92-104

29. Schmitz N, Burger J, Hasse H (2015) Ind Eng Chem Res $54: 12553-12560$

30. Schmitz N, Homberg F, Berje J, Burger J, Hasse H (2015) Ind Eng Chem Res 54:6409-6417

31. Shi M, Yu X, Wang L, Dai F, He G, Li Q (2018) Kinet Catal 59:255-261

32. Zhang J, Fang D, Liu D (2014) Ind Eng Chem Res 53:13589-13597

33. Zhang J, Liu D (2018) Int J Energy Res 42:1237-1246

34. Grünert A, Losch P, Ochoa-Hernández C, Schmidt W, Schüth F (2018) Green Chem 20:4719-4728

35. Hollemann AF, Wiberg E, Wiberg N (2007) Lehrbuch der anorganischen Chemie, vol 102. Walter de Gruyter, Berlin

36. Villadsen J, Livejerg H (1978) Catal Rev Sci Eng 17:203-272

37. Krawietz TR, Lin P, Lotterhos KE, Torres PD, Barich DH, Clearfield A, Haw JF (1998) JACS 120:8502-8511

38. Malaika A, Rechnia-Goracy P, Kot M, Kozłowski M (2018) Catal Today 301:266-273

39. Cavani F, Girotti G, Terzoni G (1993) Appl Catal A 97:177-196

40. Thommes M, Kaneko K, Neimark AV, Olivier JP, RodriguezReinoso F, Rouquerol J, Sing KSW (2015) Pure Appl Chem. https ://doi.org/10.1515/pac-2014-1117

41. Crutchfield MM, Callis CV, Irani RR, Roth GC (1962) Inorg Chem 1:813-817

42. Lischke G, Eckelt R, Jerschekewitz H-G, Parlitz B, Schereier E, Storek W, Zibrowius B, Öhlmann G (1991) J Catal 132:229-243

Publisher's Note Springer Nature remains neutral with regard to jurisdictional claims in published maps and institutional affiliations. 